\title{
Rhythmical coordination of performers and audience in partner dance: delineating improvised and choreographed interaction
}

\author{
Saul Albert (saul.albert@qmul.ac.uk)
}

\section{Contents}

2 Data and methods $\quad 4$

2.1 Rhythm and interaction in a Lindy hop performance . . . . . . . . . . . . . . . . 4

2.2 Studying the attention structure of an audience through rhythm $\ldots \ldots \ldots$

2.3 Describing varied, coupled rhythms in the performance setting . . . . . . . . . . . 7

3 Analysis $\quad 9$

3.1 Choreography: reorientation to familiar movements $\ldots \ldots \ldots$

3.2 Improvisation: displays of readiness to change . . . . . . . . . . . . . . . . . 13

3.3 Embodied action: joint coordination of improvised movement . . . . . . . . . . . . . . . . 14

4 Discussion $\quad 17$

4.1 Analytic distinctions between improvisation and choreography . . . . . . . . . . . . . 17

4.2 Embodied rhythms as projectable, interactional resources . . . . . . . . . . . . . 18

4.3 Embodied action built with non-vocal resources f . . . . . . . . . . . . . . . . . . 19

5 Conclusion $\quad 21$

6 Acknowledgements $\quad 21$

7 References $\quad 21$ 


\begin{abstract}
This paper explores rhythm in social interaction by analysing how partner dancers and audience members move together during a performance. The analysis draws an empirical distinction between choreographed and improvised movements by tracking the ways participants deal with variations in the projectability and contingencies of upcoming movements. A detailed specification of temporal patterns and relationships between rhythms shows how different rhythms are used as interactional resources. Systematic disruptions to their rhythmical clapping shows how audience members work with dancers to sustain the accountability and relevance of mutual coordination. This reveals how dancers initiate, sustain and complete distinct phases of spontaneous movement as embodied social action.
\end{abstract}

Keywords: interaction; dance; ethnomethodology 


\section{Introduction}

What can audience members' embodied, rhythmical movements tell us about their experience of a musical dance performance? And what do their responses reveal about the composition, organisation and production of the performance itself? Seated in a concert hall, individual listeners may display few outward signs of their rhythmical involvement. However, cross-cultural studies of music suggest that clear distinctions between playing, listening to and dancing to music are relatively unusual (S. Brown \& Jordania, 2011). Some less 'concertised', vernacular performance settings (Jackson, 2001) encourage audiences to stamp their feet, snap their fingers, clap, move and vocalise along with performers. In musical traditions without fixed compositions such as improvised jazz, displays of rhythm also do more than keep metronomic time (Sudnow, 2001 p.98). These rhythms are sometimes analytically defined using musicological and computational descriptions that specify the patterns of 'swing' or 'groove' (Pressing, 2002). However, participants' varied understandings of these rhythms are reflected in practice by the way they interact: listening, responding and adjusting to one another's improvisational play (Duranti \& Burrel, 2004; Healey, Leach, \& Bryan-Kinns, 2005; Schober \& Spiro, 2014). Each member of a jazz band treats rhythm differently depending on their instrument, their improvisational role, and the work they are called upon to do as band members to support and augment the playing of others (Gibson, 2010). Amongst a broader ensemble of players, dancers, and an audience, the flexibility of these rhythms means that responding to something as 'correct' or 'incorrect' is a judgement through which the establishment and maintenance of cultural norms remains a constant, practical issue for all participants (Becker, 1984, pp. 203-204; Black, 2008). As they move together, partnered dancers, audiences and musicians work to maintain their individual coordination to various 'external' rhythms in the music, as well as their mutual coordination with one another (Chauvigné, Gitau, \& Brown, 2014). Divergences of synchrony between rhythms and participants' methods for rectifying problems of coordination are made observable and evident as issues for participants and analysts alike.

Vernacular partner dance performances therefore provide a 'perspicuous setting' (Garfinkel \& Wieder, 1992) for observing how rhythms are used to coordinate joint action. Building on ethnomethodological studies of how audiences, performers and performances are constituted as such through social interaction (Broth, 2011; Gardair, 2013; C. Goodwin, 1986), this article focuses on five seconds of a partner dance performance to show how audience members and dancers work together to use, produce and reflexively constitute varied rhythmical patterns. A simple framework is used for describing how rhythmical patterns are causally coupled as in, for example, orderly periodic clapping, or uncoupled clapping, as in bursts of cacophonous applause. This enables the central single case analysis, which suggests several starting points for exploring how participants make sense of sequences of movement together as social actions. Firstly, participants coordinate shifts in their activities to deal with the varying levels of projectability of upcoming dance movements. Analysis of these shifts reveals how participants themselves make distinctions between set piece, choreographed moves and sequences of improvised movement. Secondly, these distinctions show how partner dancers use physical connection to mobilise or constrain each other's movements differently during improvisation or set piece moves. The analysis details how audience and dancers coordinate joint movements by combining bodily resources such as touch, resistance, and mutual balance with visible resources such as gaze and body orientation along with a-priori mutual knowledge and experience of the dance. Audience members' responses also show how they use some of these resources and shared knowledge to differing extents. Focusing on rhythm as a key common resource shows how, by synchronising varied rhythmical patterns and structures, participants can display, assess, and recover from problems in ongoing coordination and interactional understanding. Finally, these findings are discussed alongside related studies of social interaction 
to suggest how rhythm is used amongst other resources to coordinate action within generic sense-making practices in naturalistic social settings.

\section{Data and methods}

\subsection{Rhythm and interaction in a Lindy hop performance}

The way jazz improvisers balance familiar musical structures and well-known standards with moments of spontaneous improvisation (Duranti \& Burrel, 2004; Gibson, 2010) is reflected in the practice of the 'social dance'. In social dances, conventional patterns and set piece 'moves' are strung together with spontaneously coordinated improvisations. The Lindy hop is a social dance first developed by African American dancers combining the many cultural influences in Harlem in the late 1920s to the music of the swing era jazz bands (Batiuchok, 1988). Without the 'masterplan' that would be provided by a fixed choreography (equivalent to a rehearsed musical score (Haviland, 2011; Weeks, 1990)) social dancers work as improvising performers, and draw on other features of their local environment and prior experience to structure the dance. The conventional phrasing and even tempo of recorded music provides one obvious mutual resource for coordination. For example, social dancers of Lindy hop or tango can use music as an 'external' point of reference for rhythmical synchrony. The music in the video clip analysed below is from Jeep Jockey Jump by the Glenn Miller Army Airforce Band (Grammercy Records, 2013): a Swing Jazz arrangement by Jerry Gray typical of the big band music played during Lindy hop social dances. Dancers learn to structure their movements using the phrasing of typical swing jazz arrangements, which usually follow a predictable pattern. After an introduction when dancers sway together in preparation for joint movement, a phrase structure begins, each comprising 32 beats of a 4/4 rhythm (Jackson, 2001). Phrases can be broken down further into four 'eights', and the last eight in each phrase conventionally features a melodic or rhythmical break that highlights an instrumental solo or some other distinctive variation in the music. Many set piece moves taught in Lindy hop comprise sets of six or eight beat footwork patterns, and skilled dancers will string together sequences of moves that match the projectable length of a phrase.

The data analysed here feature professional Lindy hop dancers Michael Seguin and Frida Segerdahl participating in a 'Jack and Jill' performance competition. In this format partners are chosen at random from the row of seated competitors, in this case all professionals, shown in Figure 1, only a few seconds before they have to perform. This YouTube video (Lindy Library, 2013) ${ }^{1}$ shows competitors dancing on stage, with two event organisers on the left, and is shot from the perspective of the audience and judges, who are seated in a semi-circle on the floor, occasionally silhouetted at the bottom of the frame. In a social partner dance, the central roles are the 'leader' and 'follower'. In Lindy hop, partners maintain one of several 'basic' conventional footwork patterns on top of which the leader initiates movements and the follower responds. Over the course of a social dance, these paired movements are coordinated into improvised sequences. In terms of participation, it is important to clarify two ways that the terms leader and follower are used here. Firstly, Ravignani, Bowling, \& Fitch (2014) use technical descriptions of cross-species group 'chorusing' behaviours to describe how individual leaders and followers in both human dance and animal behaviour can produce identically patterned rhythms, but 'leaders' stay ahead by a consistent temporal offset. Secondly, in partner dance, these conventionally gendered terms that may also suggest that the leader (usually male) always

\footnotetext{
${ }^{1}$ See https://youtu.be/puexHLZ8KQg?t=1m6s (01:08-01:20)
} 
dominates (Beggan \& Pruitt, 2013). Although these gendered norms persist in Lindy hop, they are not prescriptively determined, and today are often intentionally transgressed (Wade, 2011). This analysis focuses on how the two dancers and the visible audience comprised of their seated fellow competitors participate by moving, clapping in time, falling silent, cheering, sitting or jumping up at particular moments, and how through these actions they constitute, uphold and use the 'performance situation' (Broth, 2011; Gardair, 2013, p. 156) as a whole. This broad analytical framing enables a discussion of how both participant roles and temporal patterns are normatively achieved and adapted through an ongoing, reflexive procedure of interactional sense-making (C. Goodwin, 2007b).

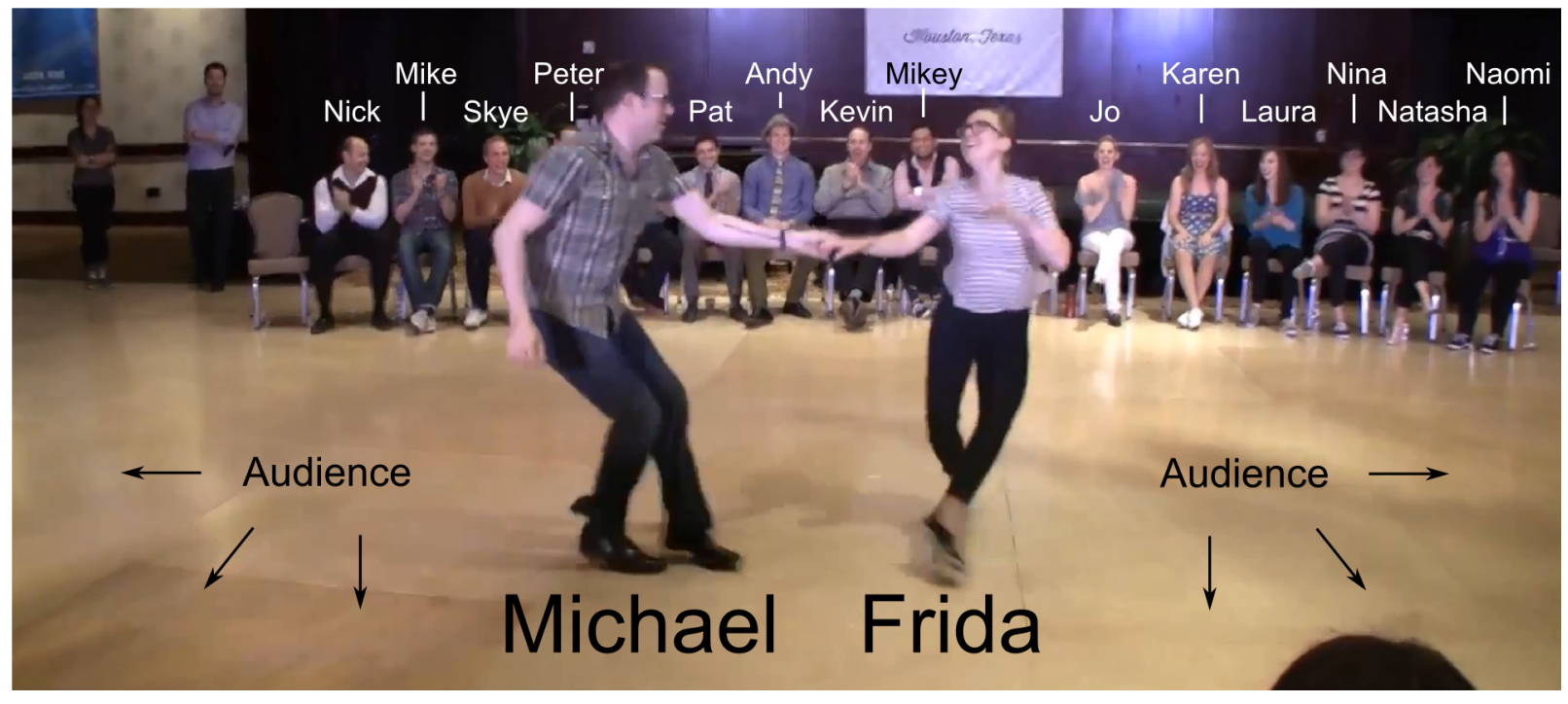

Figure 1: Dancers and other seated competitors in a 'Jack and Jill' competition .

This approach builds on ethnomethodological descriptions of the reflexive procedure through which all participants constitute their respective roles and uphold the predictable patterns and conventional structures of mundane 'performances' in everyday interaction.

"Moment by moment each party must take into account: 1) the emerging structure of the activities in progress; 2) what precisely other parties are doing; and 3) the implications that this has for the trajectory of future action." (C. Goodwin, 2007b, p. 28)

For example, Sacks $(1974,1986)$ shows how both the narrative structure and the interactional telling of a story or a joke in conversation must project what is going to happen next, deal with what is currently happening, and account for what has already happened. A conventional story preface "did I tell you about last night" projects that a story is about to be told, and that the telling will be over once the narrative reaches last night's events. The recipient has the choice at this point to answer "no", showing readiness to listen to an extended telling and to adopt the story recipient role by forgoing opportunities to talk. Once this action contingently ratifies the teller's role and the story proceeds, the recipient must then monitor the unfolding narrative carefully in order to display understanding as soon as the story concludes or the punchline emerges. Similarly, leaders and followers in a social dance do not produce identical, perfectly rehearsed movements in metronomic time. When a leader initiates a movement, the follower must choose - within certain constraints - how to respond with a different but physically compatible movement, setting new constraints on what is led 
next. So after the first move, leading and following in social dance relies on a reflexive procedure through which participants constantly monitor and adapt to the interactional contingencies of how their last action was interpreted and responded to by their partner. Normative roles such as leader and follower enable participants to use each other's experience, their bodies and actions, the music and other features of the setting opportunistically as semiotic resources in an ongoing procedure of intersubjective sense-making (C. Goodwin, 2000, 2007a; Haddington, Mondada, \& Nevile, 2013).

\subsection{Studying the attention structure of an audience through rhythm}

Beyond 'principal' roles of teller and recipient in storytelling or lead and follow in social dance, other roles may be constituted through performances in multi-party settings. Some of the earliest research on the embodied production of everyday tellings (C. Goodwin, 1979) highlighted the subtlety and diversity of multiple listeners' responses and "the importance of the attention structure that an audience brings to a performance" (C. Goodwin, 1986). Studies in conversation analysis (CA) show how participants' situationally contingent patterns of gaze, gesture and body orientation intersect with conventionalised patterns of narrative, grammar and syntactic structure (C. Goodwin, 1984; Jefferson, 1978; Schegloff, 1996). This approach treats a telling as a micro-performance, and demonstrates how co-tellers and co-recipients work together subtly to uphold both the roles and structure of a telling. CA studies suggest that larger audiences' displays of involvement and attention structure may be more constrained by institutional conventions. Atkinson (1984, p. 404) describes how the silence of audiences in his courtroom data led him to study how specific rhetorical devices in political speeches elicit "gross displays of attentiveness" such as applause (Atkinson, 1984; Heritage \& Greatbatch, 1986) or booing (Clayman, 1993). Broth (2011) compares the timing of theatre audiences' 'sanctioned' activities of applause and laughter with their 'unofficial' coughing to show their understanding of the structure of theatrical dialogue, and demonstrating their complicity in establishing and sustaining normative constraints on audience participation. Even without podium, stage, seating or a conventional performance space (Haviland, 2011; Healey et al., 2005), Gardair (2013, pp. 83-91) shows how street performers create an audience by arranging passers-by into a semi-circular group and training them to applaud on cue, and to laugh at pedestrians who may unknowingly walk through the ad-hoc stage. This analysis draws on CA and related methods of video analysis to ask what embodied displays of rhythmical coordination can reveal about participants' varied experiences of - and roles in - the co-production of a performance situation.

These methods are more usually employed in studying conversation or other embodied forms of interaction that unfold over time in relation to talk. This single case analysis of embodied rhythmical coordination in dance builds on the phenomenological roots of research into the temporal organisational structures within human action to suggest how storytellings, partner dances and other socio-aesthetic practices share similar models of intersubjectivity based on projectable, conventional patterns and the normative accountability of deviating from them. Drawing on Husserl's phenomenology of time, Schütz (1951, pp. 90-94) describes sounds in speech or music as a series of 'polythetic' steps that must be taken in sequence before meaning can be grasped retrospectively as a 'monothetic' whole. A series of beats only becomes hearable and projectable as a regular pulse after the third beat in a periodic sequence (Auer, 1990 pp.363-364). In order to respond appropriately, for example by clapping together to the beat, participants must project each step as " 'standing on behalf of' a presupposed underlying pattern" (Garfinkel, 1967, p. 78), which constantly unfolds

as a reflexively accountable sequence of actions. Schütz (1962, p. 147) highlights this temporal structure of speech and music as a "general feature of mental life itself. Whether or not it goes on as an indiscernible, 
equally structured stream, it has its characteristic pulsation, its rhythm, by which the inner duration is articulated". Music in particular provides Schütz with "a model for forms of intersubjectivity occurring in everyday life, which are not based solely or primarily on a semantic system of meaning" (Malhotra, 1981). In these terms 'internal' time is articulated through its public interaction with projectable structures of external, metronomic time. Although projecting a next step is ostensibly an internal experience, on a micro-analytic level performers and audience members can be seen dealing with split-second decisions about how to maintain temporal coordination while responding to the unfolding contingencies of situated joint action.

Analysts often use the terms 'choreography' and 'improvisation' as metaphors to explain how coordinated activities are constituted by participants combining premeditated, learned patterns with joint actions built extemporaneously using resources available in the setting (Iwasaki, 2011; Tulbert \& Goodwin, 2011; J. Whalen, Whalen, \& Henderson, 2002). The 'embodied turn' in CA studies (Nevile, 2015) has emphasised how participants use conventionalised sequences of embodied talk, gesture, and body orientation to pursue - or to constrain and reorganise courses of situated social action (C. Goodwin, 1981; Haddington et al., 2013; Hazel, Mortensen, \& Rasmussen, 2014; Heath, 1984; Schegloff, 1985). CA studies of Lindy hop workshops (Broth \& Keevallik, 2014; Keevallik, 2014) show how dance instructors combine talk, partnered movement and 'bodily-vocal demonstrations' as instructions for students to follow - and as 'corrections' for when students visibly deviate from a normatively adequate response (Keevallik, 2010). In these situations, teachers and students, or storytellers and recipients encounter 'polythetic' moments where their responses can uphold, abort, or modify the overall course of action. Participants infer ongoing shared understanding from each other's conformity with a normative pattern of initiation and response - or lack thereof (Sacks, 1987, 1995 p.113) - until the course of action is retrospectively assessable as a monothetic whole. In a partner dance, this is ostensibly achieved through choreography on the one hand: with reference to the normative regularities of 'external' musical timing and conventional responses to initiating actions, and through improvisation on the other: paced by 'internal' timing and the situated contingencies of each interaction (Sheets-Johnstone, 1981). Uncertainty about the action underway at any moment means that "deft footwork may be required to make mid-stream adjustments consequent to signs that the projections have been misunderstood" (Levinson, 1988). Observing participants' displays of greater or lesser readiness to adjust can therefore provide evidence as to how they segment, project and compose sequences of reciprocal movement. Tracking the initiation and completion of dance movements as they unfold in time can show how participants deal with varying levels of contingency, and what resources they use to project and manage joint actions during a spontaneous social dance.

\subsection{Describing varied, coupled rhythms in the performance setting}

This approach requires detailed descriptions of the various rhythms available as resources to participants and how they are coordinated in a social dance. Research into human sensorimotor entrainment provides useful examples in the way it describes the results of 'tapping experiments' that test subjects' abilities to match finger taps to a regular beat (Repp \& Su, 2013). These studies explore the relationships between sensory, cognitive and motor functions because tapping accurately to a regular beat requires 'internal' regulatory mechanisms to project the fall of the next beat and sensorimotor mechanisms to detect and correct participants' rhythmical deviations in relation to 'external' rhythms. Chauvigné et al. (2014) suggest that partner dances such as the Tango provide a naturalistic equivalent to these experimental scenarios. Figure 2 illustrates patterns of regular, periodic or irregular aperiodic 'chorusing' behaviours (Ravignani et al., 2014) with descriptions of their use in the coordination of everyday activities. This framework highlights whether 
they are regulated or 'paced' individually (walking alone), mutually (rowing in a group), or using an 'external' resource such as musical rhythm (dancing solo or in a group) or stop lights (driving off alone or in traffic). This enables detailed description of how the rhythms available in a social dance performance may be available as interactional resources for various participants. For example, in the video clip analysed below, audience members' bursts of applause and pulses of laughter can be described as an uncoupled periodic pattern. These rhythms consist of more or less equally spaced claps or laughs, but they are uncoupled between audience members resulting in the distinctive sound of applause. By contrast, the choral clapping of the audience constitutes a coupled periodic pattern. This rhythm is coupled between participants and possibly also with various rhythms in the music such as two drum beats for each clap. This descriptive framework provides some straight forward ways to describe and compare rhythmical patterns, and to infer causal relationships or 'coupling' between them by observing how they are used and modified interactionally.

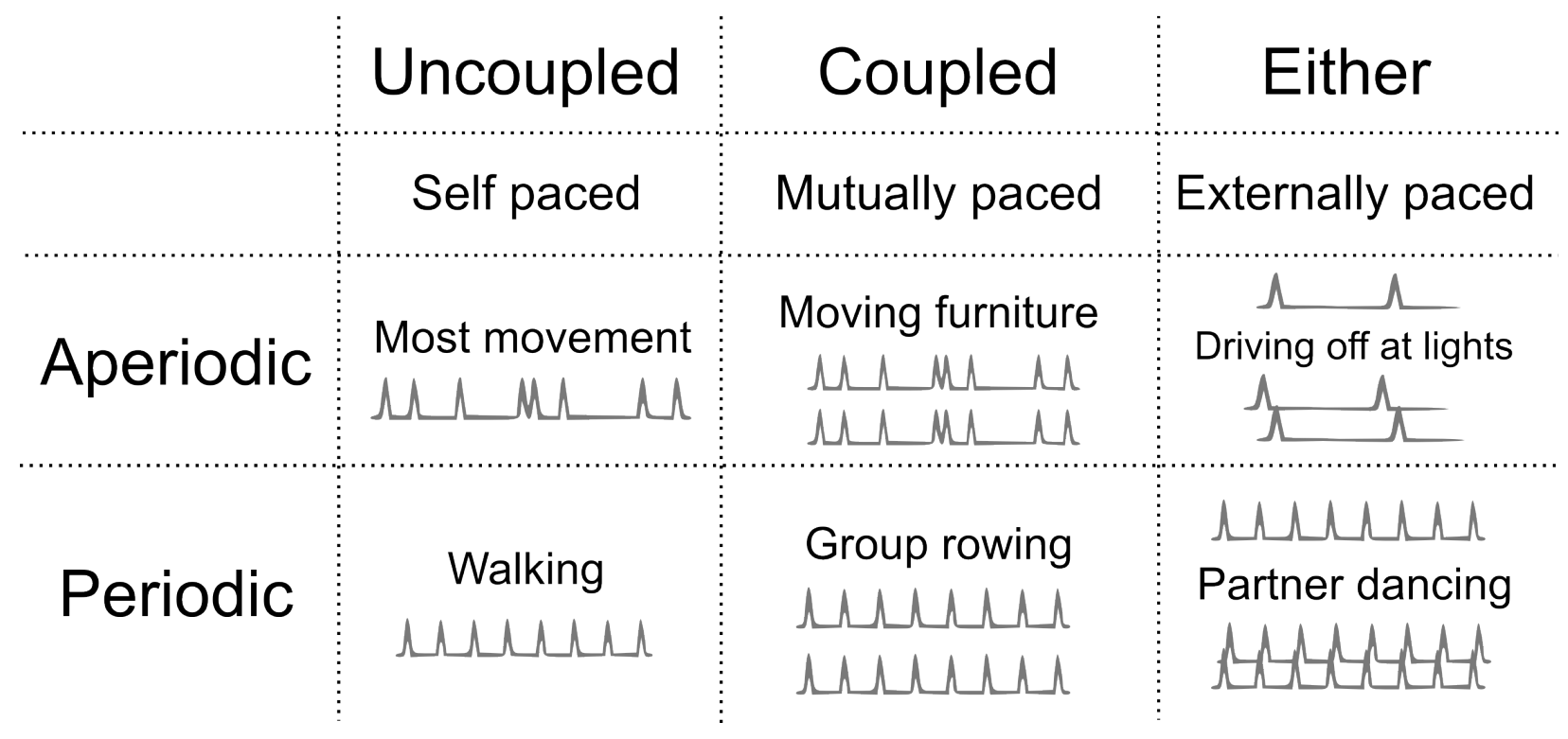

Figure 2: A simplified framework for describing patterns of rhythmical synchrony within major categories of human pacing adapted from Ravignani et al. (2014) and Chauvigné et al. (2014).

One key rhythmical resource that requires some background explanation to analyse how it is used by participants in this video clip is the conventional structure of the music. Dancers' and audience members' familiarity with the phrasing structure of swing jazz is essential to how they can use it as an interactional resource for organising improvised action. For example, the pattern of bass drum beats and audience claps suggests how a predictable, projectable structure can be used to organise a few seconds of this joint action. Within a slightly larger time window, the pattern of note shifts in the chorus refrain also provides a predictable and projectable resource. However, the precise pattern of shifts between notes in the horn solo does not repeat at any point in the song, or in other recordings of the same tune. Instead, its overall length or projected 'arrival time' for completion (Sudnow, 2001, pp. 96-100) coincides with a conventional 16 beat phrase or 'break' (Jackson, 2001), and is followed by another aperiodically structured 16-beat solo from another horn. In this way the improvisational, aperiodic structure of a solo is organised with reference to the overall regularity and projectability of the conventional orchestration. Dancers may use this overall structure, as well as responding to variations between intervals and ratios of coupled rhythms that usually occur at the end of 
each 16 or 32 beat phrase in swing jazz and related genres (Pressing, 2002). In less heavily orchestrated examples of these genres, these changes are not usually performed with such algorithmic regularity or between such fixed patterns that they constitute a larger repeating pattern of identical phrasing. Similarly, in partner dancers' shared movements, their footfalls, patterns of gaze and body orientation may be organised as regularly repeating periodic patterns, or aperiodically, with reference to the contingencies of joint action and larger conventional structures they can predict and recognise within the music.

\section{Analysis}

The starting point for this analysis is to observe changes in audience members' and dancers' behaviours that suggest shifts between more or less confidence in their ability to project the course of upcoming action. While clapping in time, or leading and following partnered movements in a social dance, participants draw on their "stock of knowledge at hand in forming anticipations of future events" (Schütz, 1976). Participants display their confidence by moving in time with the structure of a familiar tune, anticipating a conventional phrase ending, or effortlessly performing a 'set piece' move that all Lindy hop dancers have learned and practised. It is important to note that the competition filmed in this video takes place at an event where all audience members are likely to be Lindy hop dancers with a good knowledge of such 'basic' steps. Observing participants' behaviours in detail can reveal shifts between orientation to familiar set piece moves and moments where their behaviour suggests less confidence in projectable next actions: where they attend closely to the contingencies of changes in the music, to dancers' possible next actions, and to other resources in the local setting that may be useful for maintaining coordination. Rather than relying solely on the taught conventions of the dance form to distinguish one move from another analytically, these shifts of orientation provide an empirical basis for identifying the end of one 'move' or series of moves and the beginning of the next. The first section of this analysis picks out these patterns amongst audience members' and dancers movements in the course of two familiar set piece moves. The second section analyses the transition between familiar and more improvised movements in terms of the audiences' and dancers' shifts in their displays of orientation to the projectability or contingency of next actions. Finally, the last section explores an especially adept display of audience involvement in terms of how all participants work together to track and solve problems of rhythmical, temporal and embodied coordination as they emerge interactionally.

The analysis uses video stills throughout arranged in numbered rows, and (where necessary) divided into alphabetically labelled panels containing still frames that read from top to bottom and left to right, borrowing conventions from comic book graphical layouts (Laurier, 2014). These illustrations are intended to be used alongside watching the video itself, for which time code ranges are provided on the right margin of each line to facilitate locating specific points in the video.

\subsection{Choreography: reorientation to familiar movements}

Figure 3 shows the audience just before the focal section of the clip begins. Several aspects of audience response and dancers' action warrant segmenting the flow of action to start the analysis here.

Firstly, there is a coordinated and emphatic reaction from the seated row of audience-competitors. Many drop their jaws, focusing intently on the dancers, and Jo's hands freeze mid-clap until, at the moment represented in line 3, she begins to clap in time again just as Kevin pulls his hands out of his pockets and both he and then 


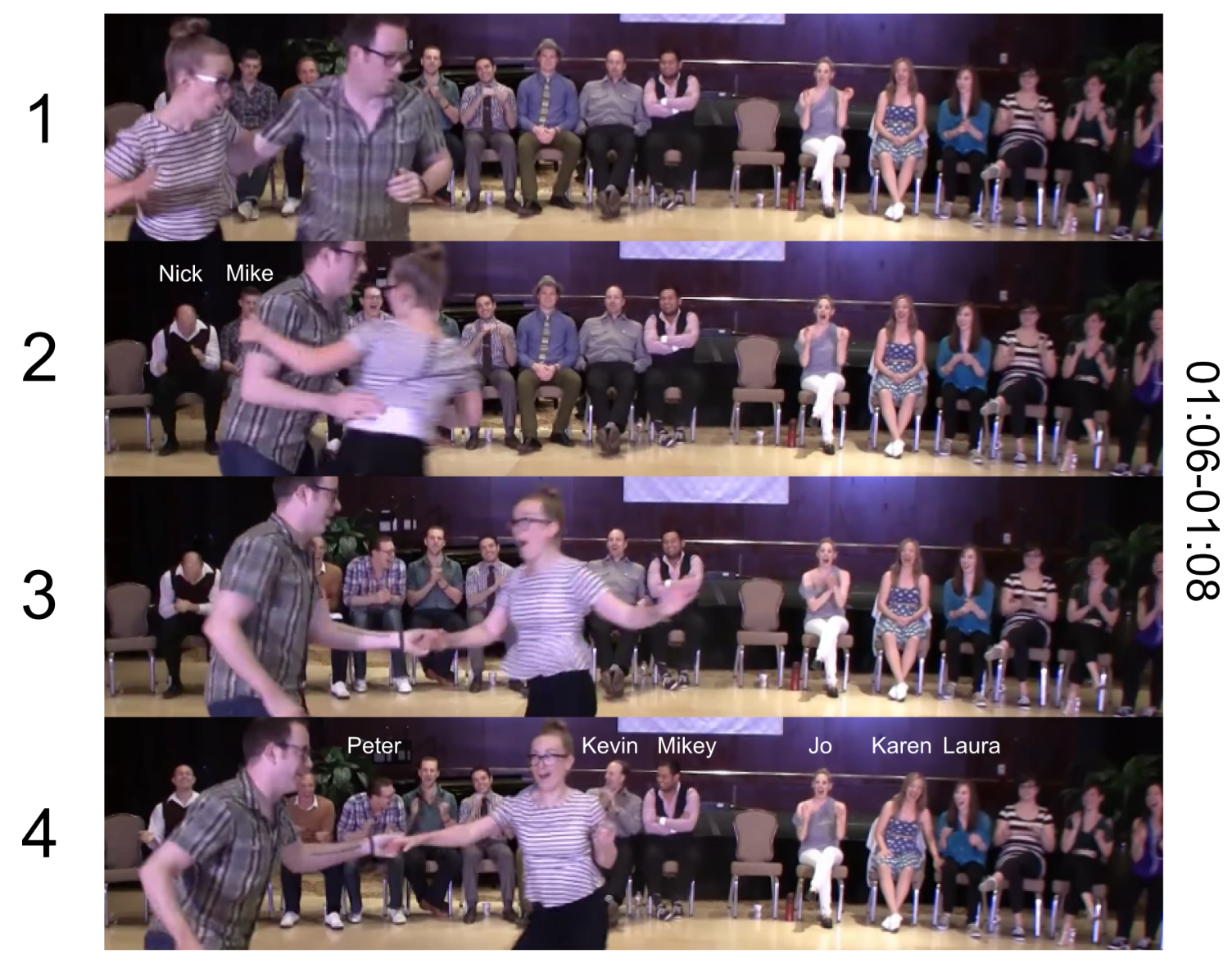

Figure 3: Audience reactions just before the focal section of the clip begins (see https://youtu. be/ puexHLZ8KQg? $t=1 \mathrm{~m} 6 \mathrm{~s}$ 01:06-01:08). 
Mike begin to clap. At first Kevin does not synchronise with others who have continued clapping together in time with the music. He claps faster, joining Peter and (audibly) off-camera audience members in a short burst of applause before synchronising with the choral clapping. Secondly, audience members use this moment to shift their attention away from the dancers and display their reactions and monitor each other's responses. Peter smiles and looks towards Mikey and Kevin in line 3, who reciprocate in line 4. Karen puts her hand on Laura's knee, who then turns and smiles towards her. These shifts in participants' displays of orientation from dancers towards each other suggests that this moment constitutes mutual sharing of a joint reaction. The way they all then turn back to the dancers further suggests this moment can be examined as the end of one recognisably response-worthy action and consequently the beginning of the next. In terms of dancers' behaviours, this moment coincides with Michael and Frida arriving face to face at mutual orientation. Changes in their facial expressions as they look towards each other suggests that this moment also displays a coordinated shift in the dancers' states of mutual attentiveness. Figure 4, which illustrates, segments and tracks the entire focal clip of the video analysed in this study starts at the moment when audience members re-orient to the dancers and the dancers orient to one another. This also marks where regular choral clapping resumes: after this point, most of the competitors seated behind Michael and Frida, and (audibly) many other audience members in the room clap clearly and regularly together once for every two beats in the music.

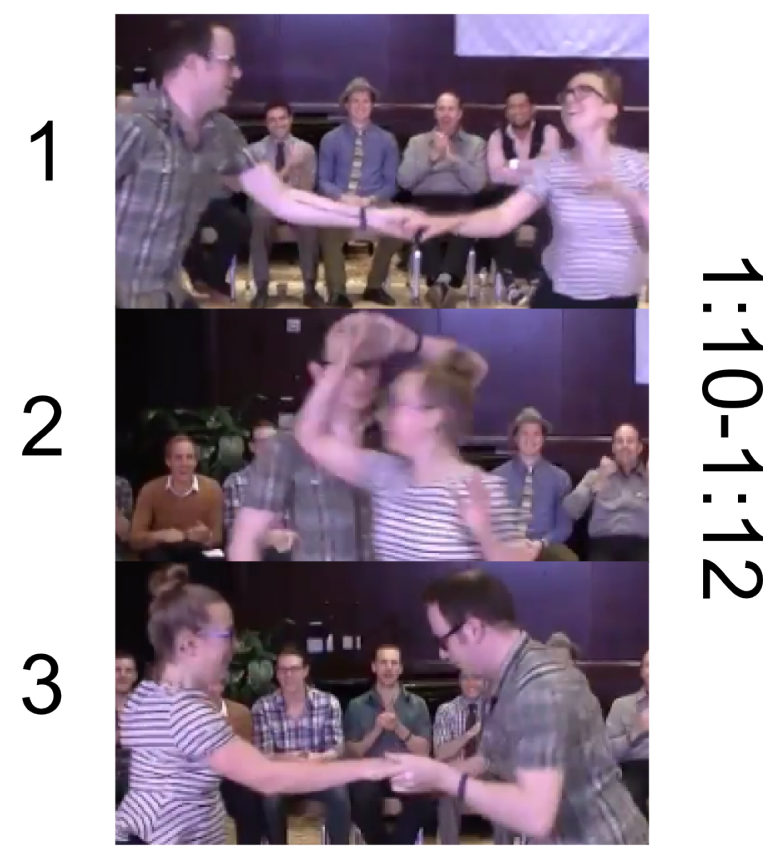

Figure 4: Visual overview of the clip with time codes (see https://youtu . be/puexHLZ8KQg?t=1m8s).

Throughout the period indicated in lines 1-2 of Figure 4, the dancers perform several highly conventionalised set piece movements. Michael and Frida do a set piece move called a 'swing-out': a traditional step that has become emblematic of the Lindy hop (Jackson, 2001), as demonstrated by William Downes and Frances “Mickey" Jones in a clip from H.C. Potter's 1941 film Hellzapoppin' (Barbican Centre, 2010) shown in Figure 5. The movement starts with leader's left hand connected to the follower's right in 'open position'. They stay facing one another while the lead brings the follow partner forwards, catches their back with the right arm and redirects their momentum in a clockwise rotation back out into open position. 


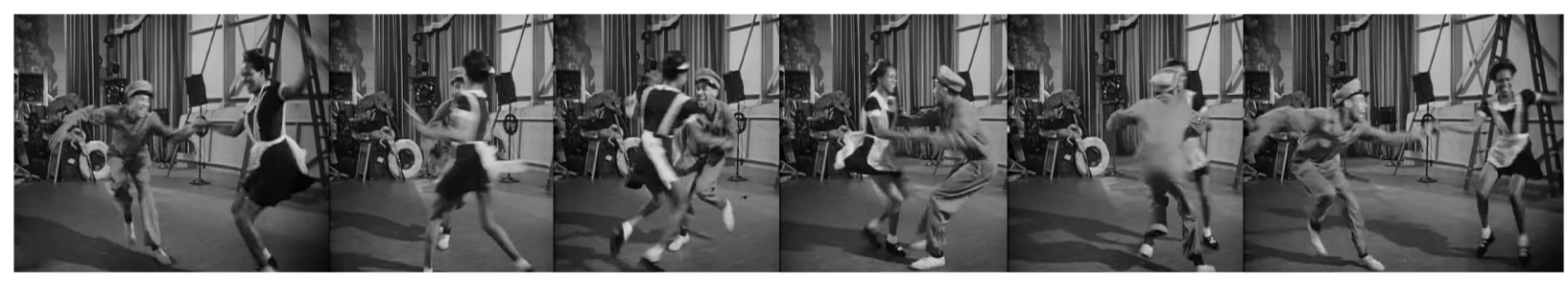

Figure 5: A 'swing-out' from Hellzapoppin' (1941) (see https : //youtu . be/qkthxBsIeGQ, 0:02-0:04).

In the last five beats of the swing-out, Frida swivels her hips away from Michael as she moves out towards open position, shifting her body weight, her head and her free arm backwards as she looks up and smiles. These movements are typical stylistic variations at the end of a swing-out, and also make Frida less able to monitor Michael's activities or meet his direct gaze, and less evenly balanced to respond quickly to any changes. To any Lindy hop dancer such as those in the audience, this movement is immediately recognisable and its completion has a projectable end point. This secures a few seconds during which constant vigilance about the emerging structure of the current activity can be relaxed. The audience's continued, regular choral clapping and Frida's non-readiness for change suggest that neither audience nor dancers anticipate immanent modification of the predictable structure of next few rhythmical claps or the next five footfalls within the conventional footwork pattern of the swing-out.

The period during which audience members display confidence in the stable and ongoing structure of their joint participation in choral clapping ends when Kevin freezes mid-clap at Figure 4, panel $2 \mathrm{C}$ followed in turn by Jo, Nina, Mike and Naomi and - audibly - many other audience members. The way their clapping continues past the conventional end of the set piece swing-out at panel $1 D$ suggests that participants are also able to project the course of the next movement - at least until Kevin's clapping is disrupted. Illustrated in line 2, this movement - also a highly recognisable Lindy hop move known as a 'pass-by' starts from the same open position as the swing-out and involves dancers changing places: the lead moves back to draw the follow past on their right, the follow rotates anti-clockwise, facing the lead as they 'pass by'. Frida's behaviour at the beginning of this movement also suggests she initially treats it as a pass-by - and as a continuation of predictable and projectable movement. As she passes Michael in panel 2B, Frida, still smiling, does not closely monitor Michael. She maintains her forward head orientation until the very last moment, whereas he tracks her movement carefully until they finish the change of place in panel $2 \mathrm{C}$. This asymmetry in their patterns of mutual monitoring is reflected in the visible asymmetry in the respective degrees of muscular tension held in their arms and shoulders (see Figure 6). Partner dancers can use this as a communicative resource by varying and working to match each other's muscular tension in a technique known as 'frame matching' (DeMers, 2013).

In Figure 4, panel 2C, as Frida's arm begins to relax into open position, Michael crooks his elbow, raising the tension between their arms. Frida 'matches', stabilising and limiting her continued movement as Michael looks down and begins to spin. At this moment Frida's smile drops away and she focuses intently, head still, balanced, carefully monitoring the newly emerging activity. Kevin freezing mid-clap here marks this as a point of incipient change where a period of joint action and projectable choreographic movement is disrupted and a subsequent spate of improvised movement begins. 


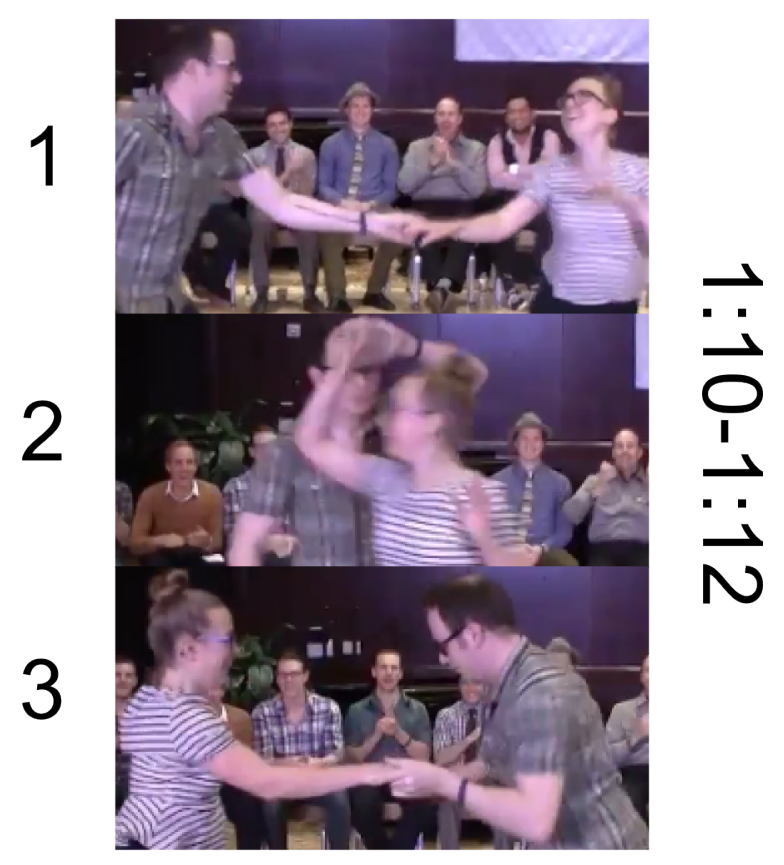

Figure 6: Matched frame (1) before, (2) during and mismatched frame (3) after the pass-by.

\subsection{Improvisation: displays of readiness to change}

Changes in participants' readiness, orientation and intensity of focus mark a clear shift from involvement in a recognisable, projectable activity into a spate of less predictable movement that will have to be monitored carefully as it develops in order to be able to manage any contingencies that may arise. This is most evident when the coordination of relatively simple joint activities such as clapping breaks down in a systematically structured way.

During the action depicted in line 3, Figure 4, first Kevin freezes at panel 3B, then after one clap, Jo freezes at $3 C$, another clap then Nina at $3 D$ and Mike and Laura on the next clap at $3 F$. Finally when the next clap is due at $4 A$, the extent of the breakdown in choral clapping is reached as Nina is the last to freeze and the following clap is audibly much quieter and less distinct. This rhythmically segmented breakdown may reflect individual and possibly also group differences in audience members' attentive focus and abilities to respond to changes in several ways. Firstly, as each of the competitors seated on the right - all women competing as followers - stops clapping, they hold their hands apart, ready and prepared to start clapping again. By contrast - of all the men competing as leads - only Kevin and Mike stop clapping at all, and they do not display such readiness to resume. Kevin puts his hands on his lap, and Mike clasps his together. These differences may reflect systematic, role-based differences in training and readiness to respond: those most used to dancing as follows may be more attuned to reacting to unexpected changes. Secondly, the order in which they stop clapping may reflect variations in their degrees of experience and sensitivity to change. Kevin and Jo - the first two to freeze - are professional dance partners and are amongst the most experienced dancers present. The breakdown in the audience's choral clapping in time traces their shift, clap-by-clap, from mutual bodily involvement in predictable rhythmical structures in the music, towards individual involvement in the more highly contingent dynamics and projectability of Michael and Frida's movements.

The dancers' movements are still projectable for the audience in the way they visibly use each other's 
momentum, arm connection, frame and the mechanical tensions generated between them to physically mobilise or constrain their partner. During less projectable, improvised movement, Michael and Frida also rely more on physical constraints to keep track of each other's position and momentum, alternating use of these physical constraints with close visual monitoring. For example, the onset of Michael's tense hold on Frida's right arm in line 3, panels A-C in Figure 4, occurs at the first moment he cannot monitor her visually, while he is spinning and looking down or away from her. During his spin Frida monitors Michael carefully, keeping her head still and level, her arm providing him with a physical anchor point and aid to balance. Michael maintains this stabilising hand hold until his spin is complete in panel $3 C$ when he lets go, transferring his momentum to Frida who then spins as he watches her carefully over his right then his left shoulder in panel $3 E$. Here Frida also keeps her head position fixed on Michael while moving into her spin, whipping her head around to refocus on him and stopping herself just before crashing into the physical constraint provided by his body position. These methods of keeping track of a partner visually or controlling their movement with hand connection or body position are more necessary during improvisation when partnered dance movements must be coordinated spontaneously, without the availability of of mutual anticipation of a set piece move as a resource.

\subsection{Embodied action: joint coordination of improvised movement}

In the spate of improvised movement shown in line 4 of Figure 4, both dancers and audience members display especially closely coordinated participation, especially in the latter section of this movement during the jump where the dancers' hands are not even physically connected. Jo raises her arms in panel $4 D$ simultaneously with Michael and Frida's similar movement, displaying an especially fine degree of projection and joint coordination between the audience and the dancers. Jo is not the only one to respond in this way. Most competitors performing as followers including Karen, Laura, Nina and Naomi also respond by raising their arms or shrugging their shoulders in time with the dancers' jump at panel $4 \mathrm{C}$. This closely timed coordination occurs during a period of improvisation, when neither the projectable rhythmical pattern of a regular beat, nor choreographed set piece moves are available as interactional resources. This suggests that other kinds of resources for organising joint are used by these audience members to perform such precisely timed simultaneous movements along with the jump. One such resource that would be available to this audience as dancers themselves is indicated by the way that the overall duration of this improvisational phase corresponds to 16-beats in the music. This suggests that the shifts between choreography and improvisation are themselves coupled with a larger rhythmical structure broadly corresponding to half a phrase in the conventional 32-beat phrasing of a swing jazz arrangement. However, this resource is insufficient to explain the diverse coordinated responses of audience members' applause, laughter and especially the accomplishment of the simultaneous jump. The way participants respond in these different ways at the same time suggests that they use a variety of resources for projecting the relevance of ongoing courses of movement and activity that all converge on this as the relevant moment for joint completion.

Analysing the dancers' activity leading to the jump as the joint completion of an improvised course of shared movement shows how audience members and dancers use whatever resources are currently at hand to follow a step-by-step procedure of split-second reasoning to project what comes next during improvisation. From panels 3E-4A of Figure 4, Michael and Frida coordinate stopping themselves spinning using mutual gaze. Michael initiates the spin at the last frame of panel $3 E$ by twisting his torso into Frida's hand, pushing her into a clockwise spin using his back. He checks over his shoulder before turning himself counterclockwise, whipping his head around quickly to meet Frida face-to-face as she continues her turn past him 
as shown across panel 4A. Here Frida's body continues spinning: her feet, hips and torso keep turning clockwise while her head maintains a fixed position, holding mutual gaze with Michael as he turns his body into line with his head and stops himself squarely facing her. At the last frame in panel $4 A$ Frida stops herself spinning, bracing her knees to arrest her turn and adjusting her stance to face Michael in panel $4 B$. Unlike any other dance movements in the performance, this change in mutual momentum is led and - a moment later - followed without touch. The latter two images in panel $4 \mathrm{~A}$ demonstrate the split-second process of interactional reasoning that Frida uses to stop herself spinning here. As Frida comes around to face Michael, she extends her right hand to his left: an offer that could result in a standard open position. However, Michael rejects the offer by keeping his arms stiffly unavailable by his sides. Frida, still turning, then reaches out with her left hand offering Michael a second point of possible reconnection while again, he keeps his arms pinned until stopping his own turn at the end of panel $4 B$. After a beat of mutual gaze, Frida braces to stop her own momentum and snatches her arms away, retracting her offers in panel $4 B$.

These movements can be analysed as social actions and the procedure as interactional reasoning because Frida is not just making her hands available for Michael in a set piece or as a generic follower technique ${ }^{2}$. Her reaching hands function as rejected offers. Frida actively pushes each hand down towards Michael's hands before retracting them both sharply. Michael's actions embody a series of recipient rejections. The dancers' immanent shift to face-to-face co-orientation is projected by the way Michael meets and holds Frida's gaze as he turns, stabilising his head, then untwisting his body, squaring up towards her. As he twists, Michael's arms rise with the centrifugal momentum and he actively pushes them down to his sides only at the moment that Frida's hands reach towards his. Seeing these as two rejected offers casts Frida snatching away her hands as a literal retraction, and shows how step-by-step inferences about the other's actions are visibly constituted in joint improvisation. This sense-making procedure is evidently visible and available to the audience from the way Jo participates. From panels $4 A-B$ in Figure 4, Michael lowers his arms and crouches to jump, and as Frida twists her body back towards him, both Jo, Karen and Frida grin simultaneously and they all follow the trajectory of the movement along with Laura, Nina and Naomi. The dancers land, reconnected, while the crowd behind the camera responds emphatically: competitors and judges laughing and jumping up in their seats so that even the video camera operator is either jostled or - literally - moved by the performance. Participants become physically involved in the mounting problem of figuring out 'what now, and what next' that culminates in Frida's offers and Michael's rejections. They respond to the jump as a timely solution to this interactional problem at the convergence of the projectable completion of a social action and the looming "prospective time of arrival" (Sudnow, 2001, p. 99) provided by the rhythmical and conventional structures of the music.

The resumption of choral rhythmical movement by audience and dancers after this phase of improvisation marks a shared return to predictable, choreographed joint movement. Figure 7 shows the regular structure of audible choral clapping along with Jo's suspension and resumption of her own periodic clapping rhythm. This diagram also roughly plots the pattern of each dancers' footfalls along the same timeline, demonstrating how repeating patterns of rhythmical movement are disrupted and resumed in a coordinated fashion.

This illustration of Michael and Frida's footfalls in panel of Figure 7 loosely corresponds with the duration of the two set piece moves - the swing-out and the pass-by - described above. It also shows their syncopated rhythms alongside the ongoing choral clapping and suggests how they are organised in relation to one another: as variably coupled combinations of periodic rhythms and set patterns of learned, choreographed

\footnotetext{
${ }^{2}$ Following in Lindy hop typically involves allowing ones hands to remain available during 'disconnected' spins and turns to enable leaders to optionally re-initiate contact.
} 

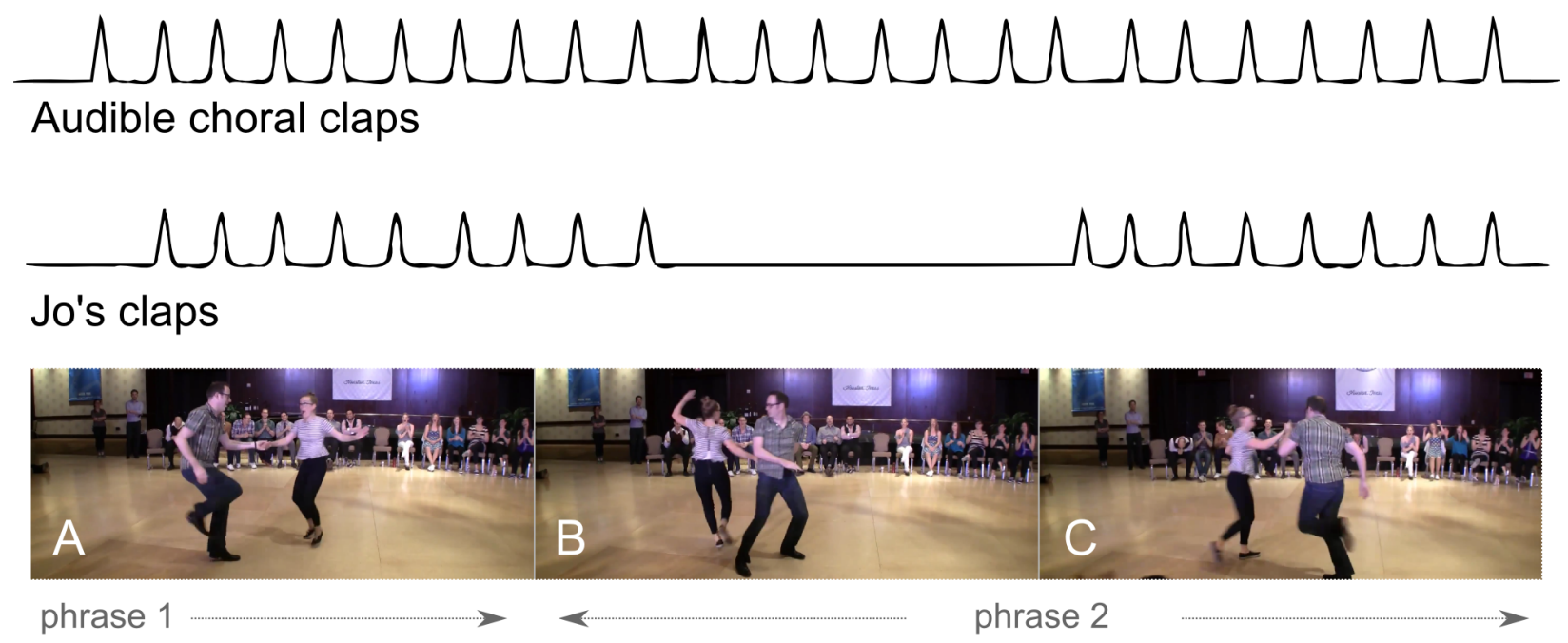

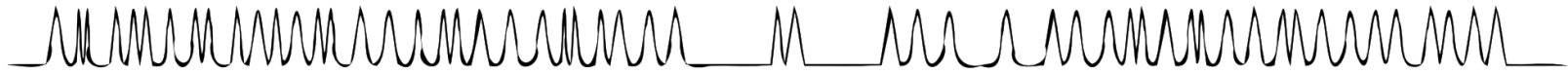
Frida's footfalls

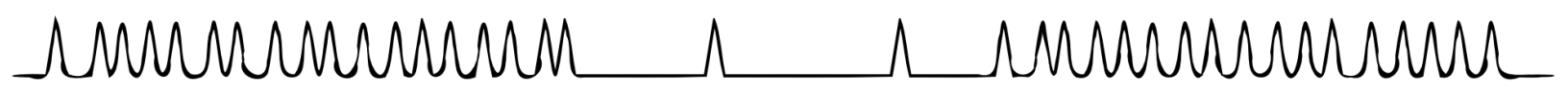
Michael's footfalls

Figure 7: Audible choral claps and musical phrases in relation to Jo's claps and each dancers' footfalls 
movement. The resumption of the footwork patterns in panel $C$ of Figure 7 shows a rough symmetry as the dancers perform the same two set piece moves in reverse order - a second pass-by followed by a swingout. The diagram also shows how these patterns are organised in relation to the conventional structure of 32 beat phrases in the music: panel $A$ shows the last 16-beat section of the previous phrase, and panels $B-C$ constitute an entire 32 beat phrase. This demonstrates how Michael's rhythmical footwork pattern first suggests his shift from choreography to improvisation at the beginning of a new phrase at panel $B$, then Frida's and Jo's disrupted rhythms indicate their reciprocal shifts within the structure of joint action. In the middle of the second phrase at panel $C$, after the first 16 beats, first Michael, then Frida, then Jo resume their repeating patterns of joint movement. This analysis suggests that the period during which participants' rhythmical patterns are non-repeating can be understood and examined further as a continual spate of improvisation between two phases of more familiar, choreographed movement.

\section{Discussion}

\subsection{Analytic distinctions between improvisation and choreography}

The first claim that can be drawn from this analysis is that participants' visible, rhythmical involvements, and their orientations to greater or lesser degrees of confidence about upcoming action constitute practical, situated distinctions between choreography and improvisation. This finding is straight-forwardly summed up by the phase structure suggested in Figure 7 which shows two spates of choral clapping and choreographic set pieces in panels $A$ and $C$ book-ending a phase of improvisation in panel $B$. This illustrates one instance of repeated occurrences of spates of improvisation book-ended by set piece movements in this way throughout the dance ${ }^{3}$. When dancers perform a series of movements not based on set piece moves that would be familiar to this expert audience, their clapping is disrupted in this way. The example analysed here simply presents a particularly clear case of a phenomenon that is observable as evidence of an audience's 'attention structure' (C. Goodwin, 1986) in most Lindy hop performances. Compared to audiences' gross displays of involvement such as applause, booing, cheering, or coughing in relation to specific rhetorical devices in political speeches or theatrical dialogue (Atkinson, 1984; Broth, 2011; Clayman, 1993), these displays provide an index of audience involvement that is constantly and evidently attuned to the unfolding performance. Some CA studies have pursued more detailed evidence of audiences' roles and responses by focusing on their rhetorical, spatial and embodied involvement in smaller participatory meetings where they may be called upon to speak (Llewellyn, 2005; Mondada, 2011) enabling more linguistic analyses. This initiative to capture audience talk points to an evidential limitation of the current study: CA research into audience involvement primarily analyses non-vocal audience behaviours in relation to performers' talk. In a survey of the increasing number of studies that deal primarily with embodied actions and non-vocal resources, Nevile (2015) shows that most still relate their analyses to participant talk and asks "for 'interaction,' must we always have talk?" This study suggests that using only non-vocal resources, participants' embodied displays of confidence in rhythmical coordination in this setting can reveal their involvements in the ongoing activities, phases and organisational structures of the performance as it unfolds. Distinguishing between improvisation and choreography through participants' displays of rhythmical coordination in this way suggests a novel analytical approach in dance research and in ethnomethodological studies of performance more broadly.

\footnotetext{
${ }^{3}$ The rest of the competition can be viewed at https: //youtu . be/xjyA0bdeA7Q.
} 


\subsection{Embodied rhythms as projectable, interactional resources}

The second key proposal drawn from this analysis is that rhythmical patterns identified in a setting such as a dance performance illustrated in Figure 8 can be analysed as interactional resources by observing how participants synchronise and deal with disruptions of synchrony between them. Revising Figure 2, this suggests how ostensible causal coupling between participants' rhythms and their pacings in relation to each other and 'external' timings in this setting are not so clearly separable in practice.

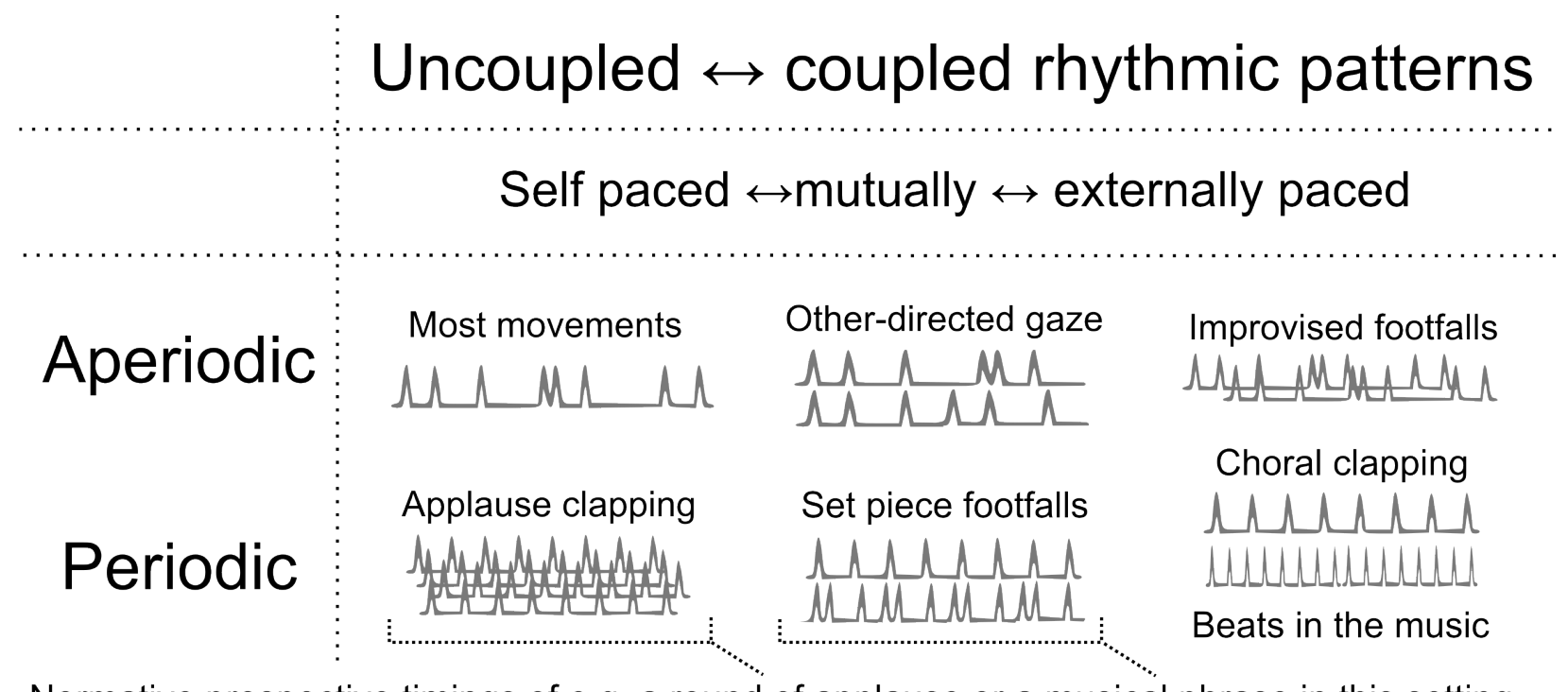

Normative prospective timings of e.g. a round of applause or a musical phrase in this setting

Figure 8: Variably patterned rhythmical resources paced and constituted by normative prospective timings

To maintain synchrony, participants evidently work to manage deviations as they occur and to adjust their timing of self-paced, mutually paced and externally paced rhythms. For example, Figure 3 line 4 shows the moment when Kevin's clapping begins as a self-paced burst of applause, then within two claps he synchronises with others' choral clapping. At this point, many more audience members' audible clapping and Peter's choral clapping is also temporarily disrupted into aperiodic applause for two beats as he and Kevin look at each other ${ }^{4}$. These claps are structured as an aperiodic, uncoupled pattern of events, but their duration as a group activity is coupled to a normative prospective timing for applause in this situation (Heritage \& Greatbatch, 1986). Similarly, phases of aperiodic dance improvisation are timed with reference to periodic or conventional patterns in the music and learned choreography. The pacing and causal relationships between rhythms are continually reconstituted through participants' practical activities in this way, which suggests that in studies of human sensorimotor synchrony through dance (Chauvigné et al., 2014), the coupling of rhythms (Ravignani et al., 2014) and a priori distinctions between their categories of pacing in Figure 2 may require careful revision in relation to the prospective normative timings available within each situation. This analysis also shows how making these kinds distinctions is crucial for understanding how individuals and groups use rhythmical patterns as resources for establishing and maintaining coordination in social interaction.

\footnotetext{
${ }^{4}$ Peter's clapping at this moment is visible on a video of the same event (PatrickAndNatasha, 2013) from a different angle see https://youtu.be/jJlR6MpMb_0?t=1m4s.
} 
Observing how these differently structured rhythms influence one another suggests that participants use them as interactional resources by combining several different kinds of projectability. For example, the audience predicts upcoming claps and accomplishes and constitutes choral clapping by projecting the timing of the next beat in a periodic rhythm (Repp \& Su, 2013). However, establishing this rhythm requires at least two events to be grasped polythetically as they occur before the third may be hearable monothetically as part of a subsequently projectable structure (Schütz, 1951). Where the rhythm has not yet emerged in an individual's clapping, they still persist in "searching for and determining pattern[s]" (Garfinkel, 1967, p. 94) as they work to make sense of unfolding events. Through this process more complex and conventionalised patterns can then emerge as 'the temporal order of events is restructured into logical 'in order to' or 'because' relationships; such that relations among actions are not restricted to consecutive events in time" (Suchman, 1987, p. 26). Like patterns of phrasing in swing jazz, or the normative length of a burst of applause, these conventionalised structures provide complementary forms of projectability based on the audience's existing 'stock of knowledge at hand' (Schütz, 1962 pp.139-148), such as their expertise as dancers. Finally, situated spatial and physical constraints also enable participants to project and reason practically - step-by-step - as to the trajectory of observed and mutual movements (Mondada, 2006). Together these complementary but varied structures of projectability can produce resources for embodied social action more generally. For example, Auer (1999 p.55) compares rhythms in speech and music and shows how participants use projectable periodic rhythms with normatively projectable lexical and grammatical structures (Auer, 2015) and physically projectable embodiment to constitute interactional resources reflexively in everyday conversation. These diverse but complementary 'projectabilities' converge at the moment of the jump, where dancers' and audiences' embodied, rhythmical involvements between the choral clapping, the familiar phrasing of the music and the dancers' visible, mobile bodies reflexively constitute a complex and articulate joint social action.

\subsection{Embodied action built with non-vocal resources}

The final claim proposed by this analysis is that the jump illustrated in Figure 4, panel $C$ is analysable as an embodied social action in similar terms with which ethnomethodological and CA studies ascribe social actions to participants in conversational talk-in-interaction. This claim builds on CA studies that use video analysis to study periods of non-vocal activity in talk (Heath, Hindmarsh, \& Luff, 2010; Nevile, 2015), and draws on novel methods within this literature for analysing and transcribing interaction where embodiment is central, such as in dance (Keevallik, 2013; Laurier, 2014). This approach contributes to CA studies of audiences (Atkinson, 1984; Broth, 2011) and related studies that pursue more detailed displays of audience attentiveness (Llewellyn, 2005). Rather than approaching this through audience participation in public speaking (Mondada, 2011), this paper builds on studies that analyse audiences' responses to periods of silence (Wooffitt \& Holt, 2010) or sudden stillness (Lan, Voilmy, Buscher, \& Hemment, 2013) that can reveal their constitutive involvements and otherwise tacit roles in maintaining the structure and organisation of the performance itself. In the setting of the Lindy hop Jack and Jill, these responses provide detailed and ongoing evidence through participants' displays of rhythmical involvement. CA studies of the 'choral production' (Lerner, 2002) of action and gesture by multiple speakers simultaneously, and how bodily-vocal actions are produced in dance instruction (Keevallik, 2010, 2014) also highlight how different kinds of projectability and rhythmical timing (Broth \& Keevallik, 2014) coordinate detailed joint actions through interactional mechanisms of initiative and response. The single case analysed here contributes to CA studies of embodiment by showing how participants use varied rhythmical structures in the setting to constitute non-vocal interactional resources that allow participants to project what is coming next in several qualitatively different ways. By 
adhering to or deviating from these variably projectable timings, participants can work together to coordinate initiations and responses to movements such as the jump in ways that constitute courses of embodied social action.

This claim suggests the possibility of extending studies of dance performance settings using collections of cases to refine and generalise characterisations of how rhythmical embodied actions are formed and recognised by participants. However, Hazel et al. (2014) describes this as a "CA paradigm" and points to some possible problems with this approach even where participants' talk is also available, citing ongoing debate as to whether (and how) complex embodied displays can be collected and studied in this way. Even in studies that focus primarily on participants' talk, CA approaches to action ascription and recognition are sometimes criticised on methodological grounds as overly intuitive and analyst-centric (Levinson, 2012). The claim for the jump being analysed as a social action - at least in as much as any CA claim - stands on evidence provided by participants' observable activities that it constitutes a sufficiently clear case of intersubjective understanding. Displays of mutual coordination are inevitably accountable as evidence of more or less secure states of intersubjective understanding (Coulter, 1979, pp. 9-34). Highly elaborate and complex cooperative actions are built through ongoing displays of precisely timed reciprocal talk and embodiment (C. Goodwin, 2013), and central to CA accounts of intersubjective understanding are robust repair mechanisms for stopping the progress of action to deal with evidence of troubles in speaking, hearing or understanding (Schegloff, 1992; Schegloff, Jefferson, \& Sacks, 1977). However, the linguistic resources required to repair troubles that may have emerged some time earlier are not so readily available to bodies moving together in time (Bassetti, 2011; Keevallik, 2010, 2014). This is even more the case in the midst of performance situations (Merlino, 2014; Weeks, 2002), where stopping and attempting to rectify troubled coordination by re-staging it would be tantamount to aborting the performance as such. Instead, as analysis of the organisation of participation in this setting has shown, participants use rhythm, conventionalised patterns of movement and physical connection to secure ongoing joint activity. But smooth, effortless coordination does not result in complex ascriptions of shared understanding.

The way the jump embodies a social action is made clear in the equally complex and sophisticated ascriptions of incompetence inferred from the official absence of timely reciprocal displays. Timing is crucial because immediately after the initiation of action, a response becomes due. For example, after a question, an answer becomes 'conditionally relevant' (Schegloff \& Sacks, 1973). Like laugher too late after a punchline (Sacks, 1974), delays or omissions of conditionally relevant items are immediately accountable as 'officially absent' (Heritage, 1984, pp. 106-110). Even short delays in response are normatively accountable as incipient disagreement or disaffiliation (Clayman, 2002; Pomerantz, 1984; Stivers, 2008). When Frida extends her arms to Michael in Figure 4 panels $4 A-B$, this becomes intelligible and projectable as an offer pending a timely, conditionally relevant acceptance or rejection by Michael. His hands-pinned-to-his sides posture then becomes intelligible as refusal. At this point their arms are disconnected, it is a moment of diminished projectability and most of the audience stop clapping. A breakdown of mutual coordination between dancers and audience is already underway. Frida and other participants can still use the rhythm and conventional structure of the music to track the normative prospective timing within which she has to make sense of and react to Michael's rejections. The timing of her anticipatory retraction of her hands can therefore be understood as responsive movements within a joint course of embodied action. The choral jump and the audiences' emphatic cheering are responsive - not necessarily to the relatively mundane physical movement - but to the way it displays recovery of joint understanding and coordination after a phase of increasing uncertainty. If Frida had jumped a moment later, this would inevitably have been accountable as an awkward failure of coordination and mutual understanding. The relief in the audiences' responses after similarly 
uncertain phases in the performance are completed are the clearest warrant to analyse these moments as social actions.

\section{Conclusion}

This study explores participants' experiences of a dance performance by asking what their displays of embodied, rhythmical involvement can reveal about the structure and organisation of their participation and the performance itself. The single case analysis of a Lindy hop dance performance suggests several related findings by documenting the emergence of a particularly emphatic audience response after the jump is coproduced as a spontaneous joint action. Firstly, this jump marks the completion of a phase of improvised movement that begins after a series of more familiar, projectable set piece moves. Shifts between these phases are visible in how audience members stop clapping and dancers adjust their orientations for immanent change in the structure and requirements of their participation. This approach distinguishes between choreography and improvisation based on participants' displays of orientation. Secondly, this analysis shows how periodic, repeating rhythms, patterns of learned choreography and conventional structures of musical phrasing function together as interactional resources. Causal relationships between rhythmical structures such as the audiences' choral clapping, dancers' learned footwork patterns and conventional musical phrasing are revealed by the way the choral clapping is disrupted as dancers deviate from set piece moves, then resume at a moment corresponding to a conventional point of completion within the musical phrasing. This suggests that participants use these relationships as a normative framework for projecting and achieving the precise timing of their own movements, and for establishing the relevance of others' timely movements in ongoing joint action. These phenomena not only indicate how causal relationships between rhythms are structured and can become intelligible as such, they also reveal systematic differences in how various individuals or groups within the audience respond: some freeze mid-clap earlier than others, or display greater or lesser degrees of bodily involvement in the unfolding joint action. Finally, this analysis shows how participants can initiate and respond to joint improvisation as mutually accountable social action - within the normative framework established through conventional, embodied and rhythmically projectable patterns of movement.

\section{Acknowledgements}

I am grateful to the editors, the two anonymous reviewers and Selene States for their careful reading and helpful suggestions. Thanks to Dirk vom Lehn, Charles Goodwin, Sandra Thompson and Gene Lerner and the Language and the Body course at UCSB for very helpful discussions and data sessions, and to Jonathan Jow for the video data.

\section{References}

Atkinson, J. M. (1984). Public speaking and audience responses: some techniques for inviting applause. In J. M. Atkinson \& J. Heritage (eds.), Structures of social action: Studies in conversation analysis (pp. 370-410). Cambridge University Press. 
Auer, P. (1990). Rhythm in telephone closings. Human Studies, 13(4), 361-392. doi:10.1007/BF00193570

Auer, P. (2015). The temporality of language in interaction projection and latency. In A. Deppermann \& S. Günthner (eds.), Temporality in interaction (pp. 27-56). Amsterdam/Philadelphia: John Benjamins Publishing Company. doi:10.1075/slsi.27.01aue

Auer, P., Couper-Kuhlen, E., \& Muller, F. (1999). Language in time: The rhythm and tempo of spoken interaction. Oxford University Press.

Barbican Centre. (2010, May 10). Lindy hop - hellzapoppin (1941). Retrieved from https://youtu. be/ qkthXBsIeGQ

Bassetti, C. (2011, August). Performative learning: Self- and other-initiated corrections in dance. Paper presented at the annual meeting of the American Sociological Association Annual Meeting, Caesar's Palace, Las Vegas, NV Online.

Batiuchok, M. (1988). The lindy (Master's thesis). New York University, New York, NY.

Becker, H. S. (1984). Art worlds. Berkeley: University of California Press.

Beggan, J. K., \& Pruitt, A. S. (2013). Leading, following and sexism in social dance: change of meaning as contained secondary adjustments. Leisure Studies, 33(5), 508-532. doi:10.1080/02614367.2013.833281

Black, S. P. (2008). Creativity and learning jazz: The practice of "listening". Mind, Culture, and Activity, 15(4), 279-295. doi:10.1080/10749030802391039

Broth, M. (2011). The theatre performance as interaction between actors and their audience. Nottingham French Studies, 50(2), 113-133.

Broth, M., \& Keevallik, L. (2014). Getting Ready to Move as a Couple: Accomplishing Mobile Formations in a Dance Class. Space and Culture, 17(2), 107-121. doi:10.1177/1206331213508483

Brown, S., \& Jordania, J. (2011). Universals in the world's musics. Psychology of Music, 41(2), 229-248. doi:10.1177/0305735611425896

Chauvigné, L. A. S., Gitau, K. M., \& Brown, S. (2014). The neural basis of audiomotor entrainment: an aLE meta-analysis. Frontiers in Human Neuroscience, 8. doi:10.3389/fnhum.2014.00776

Clayman, S. E. (1993). Booing: The anatomy of a disaffiliative response. American Sociological Review, 110-130.

Clayman, S. E. (2002). Sequence and solidarity. In E. J. Lawler \& S. R. Thye (eds.), Advances in group processes: Group cohesion, trust and solidarity (Vol. 19, pp. 229-253). New York: Elsevier Science. doi:10.1016/S0882-6145(02)19009-6

Coulter, J. (1979). The normative accountability of human action. In The Social Construction of Mind: Studies in Ethnomethodology and Linguistic Philosophy. (pp. 9-34). London; Basingstoke: The Macmillan Press.

DeMers, J. D. (2013). Frame matching and $\delta P$ t eD: a framework for teaching swing and blues dance partner connection. Research in Dance Education, 14(1), 71-80. doi:10.1080/14647893.2012.688943

Duranti, A., \& Burrel, K. (2004). Jazz improvisation: A search for hidden harmonies and a unique self. Ricerche Di Psicologia, 27(3), 71-101.

Gardair, C. (2013). Assembling Audiences (PhD thesis). Queen Mary University of London. 
Garfinkel, H. (1967). Studies in ethnomethodology. Englewood Cliffs, New Jersey: Prentice-Halll.

Garfinkel, H., \& Wieder, D. L. (1992). Two incommensurable, asymmetrically alternate technologies of social analysis. In G. Watson \& R. M. Seiler (eds.), Text in context: Contributions to ethnomethodology (pp. 175206). Newbury Park, CA: Sage New York.

Gibson, W. (2010). The group ethic in the improvising jazz ensemble: A symbolic interactionist analysis of music, identity, and social context. Studies in Symbolic Interaction, 35, 11-28. doi:10.1108/S01632396(2010)0000035005

Goodwin, C. (1979). The interactive construction of a sentence in natural conversation. In G. Psathas (ed.), Everyday language: Studies in ethnomethodology (pp. 97-121). New York, NY: Halsted Press.

Goodwin, C. (1981). Conversational Organization: interaction between speakers and hearers. New York, London: Academic Press.

Goodwin, C. (1984). Notes on story structure and the organization of participation. In J. Atkinson \& J. Heritage (eds.), Structures of social action: Studies in conversation analysis (pp. 225-246). London: Cambridge University Press.

Goodwin, C. (1986). Between and within: Alternative sequential treatments of continuers and assessments. Human Studies, 9(2), 205-217.

Goodwin, C. (2000). Action and embodiment within situated human interaction. Journal of Pragmatics, 32(10), 1489-1522.

Goodwin, C. (2007a). Environmentally coupled gestures. In S. D. Duncan, J. Cassell, \& E. T. Levy (eds.), Gesture and the dynamic dimensions of language: Essays in honor of david mcNeill (pp. 195-212). Amsterdam/Philadelphia: John Benjamins. doi:10.1075/gs.1.18goo

Goodwin, C. (2007b). Interactive footing. In E. Holt \& R. Clift (eds.), Reporting talk (pp. 16-46). Cambridge: Cambridge University Press.

Goodwin, C. (2013). The co-operative, transformative organization of human action and knowledge. Journal of Pragmatics, 46(1), 8-23. doi:10.1016/j.pragma.2012.09.003

Grammercy Records. (2013, January 17). Glenn Miller - Jeep Jockey Jump. Retrieved from https:// wWw . youtube . com/watch?v=ke_mUrZS - Qs

Haddington, P., Mondada, L., \& Nevile, M. (2013). Interaction and mobility: Language and the body in motion. (P. Haddington, L. Mondada, \& M. Nevile, eds.). Berlin, Boston: De Gruyter.

Haviland, J. B. (2011). Musical spaces. In J. Streeck, C. Goodwin, \& C. LeBaron (eds.), Embodied interaction: Language and body in the material world (pp. 289-304). Cambridge, UK: Cambridge University Press.

Hazel, S., Mortensen, K., \& Rasmussen, G. (2014). Introduction: A body of resources - CA studies of social conduct. Journal of Pragmatics, 65, 1-9. doi:10.1016/j.pragma.2013.10.007

Healey, P. G., Leach, J., \& Bryan-Kinns, N. (2005). Inter-play: Understanding group music improvisation as a form of everyday interaction. In Proceedings of less is more - simple computing in an age of complexity. Cambridge: Microsoft Research Cambridge. 
Heath, C. (1984). Talk and recipiency: Sequential organization in speech and body movement. In J. M. Atkinson \& J. Heritage (eds.), Structures of social action: Studies in conversation analysis (pp. 247-265). Cambridge University Press. doi:10.1017/CBO9780511665868.017

Heath, C., Hindmarsh, J., \& Luff, P. (2010). Video in qualitative research: analysing social interaction in everyday life. London: Sage Publications.

Heritage, J. (1984). Garfinkel and ethnomethodology. Cambridge: Polity Press.

Heritage, J., \& Greatbatch, D. (1986). Generating applause: A study of rhetoric and response at party political conferences. American Journal of Sociology, 92(1), 110-157.

Iwasaki, S. (2011). The multimodal mechanics of collaborative unit construction in Japanese conversation. In J. Streeck, C. Goodwin, \& C. LeBaron (eds.), Embodied interaction: Language and body in the material world (pp. 106-120). Cambridge: Cambridge University Press.

Jackson, J. D. (2001). Improvisation in african-american vernacular dancing. Dance Research Journal, 33(2), 40-53. doi:10.2307/1477803

Jefferson, G. (1978). Sequential aspects of storytelling in conversation. In J. Schenkein (ed.), Studies in the organization of conversational interaction (pp. 219-248). New York, NY: Academic Press.

Keevallik, L. (2010). Bodily Quoting in Dance Correction. Research on Language \& Social Interaction, 43(4), 401-426. doi:10.1080/08351813.2010.518065

Keevallik, L. (2013). The interdependence of bodily demonstrations and clausal syntax. Research on Language \& Social Interaction, 46(1), 1-21. doi:10.1080/08351813.2013.753710

Keevallik, L. (2014). Turn organization and bodily-vocal demonstrations. Journal of Pragmatics, 65, 103120. doi:10.1016/j.pragma.2014.01.008

Lan, K., Voilmy, D., Buscher, M., \& Hemment, D. (2013). The sociality of stillness. In P. Haddington, L. Mondada, \& M. Nevile (eds.), Interaction and mobility: Language and the body in motion (pp. 371-406). Berlin: De Gruyter.

Laurier, E. (2014). The graphic transcript: Poaching comic book grammar for inscribing the visual, spatial and temporal aspects of action. Geography Compass, 8(4), 235-248. doi:10.1111/gec3.12123

Lerner, G. H. (2002). Turn-sharing: The choral co-production of talk-in-interaction. In C. E. Ford, B. A. Fox, \& S. A. Thompson (eds.), The language of turn and sequence (pp. 225-257). New York: Oxford University Press USA.

Levinson, S. C. (1988). Putting linguistics on a proper footing: Explorations in Goffman's concepts of participation. In P. Drew \& A. J. Wootton (eds.), Goffman: Exploring the interaction order (pp. 161-227). Oxford: Polity Press.

Levinson, S. C. (2012). Action formation and ascription. In J. Sidnell \& T. Stivers (eds.), The handbook of conversation analysis (pp. 101-130). Cambridge: Cambridge University Press.

Lindy Library. (2013, March 19). Lone Star Championships \& Lindyfest 2013 Invitational Jack \& Jill - Michael Seguin \& Frida Segerdahl. Retrieved from http ://WWw . youtube. com/watch?v=puexHLZ8KQg

Llewellyn, N. (2005). Audience participation in political discourse: A study of public meetings. Sociology, 39(4), 697-716. doi:10.1177/0038038505056028 
Malhotra, V. A. (1981). The social accomplishment of music in a symphony orchestra: A phenomenological analysis. Qualitative Sociology, 4(2), 102-125.

Merlino, S. (2014). Singing in "another" language: how pronunciation matters in the organisation of choral rehearsals. Social Semiotics, 24(4), 420-445. doi:10.1080/10350330.2014.929390

Mondada, L. (2006). Participants' online analysis and multimodal practices: projecting the end of the turn and the closing of the sequence. Discourse Studies, 8(1), 117-129. doi:10.1177/1461445606059561

Mondada, L. (2011). The interactional production of multiple spatialities within a participatory democracy meeting. Social Semiotics, 21(2), 289-316. doi:10.1080/10350330.2011.548650

Nevile, M. (2015). The embodied turn in research on language and social interaction. Research on Language and Social Interaction, 48(2), 121-151. doi:10.1080/08351813.2015.1025499

PatrickAndNatasha. (2013, March 19). Lindyfest 2013 - LSC - Invitational Lindy Jack and Jill. Retrieved from https: //www. youtube. com/watch?v=jJlR6MpMb_o

Pomerantz, A. (1984). Agreeing and disagreeing with assessments: Some features of preferred/dispreferred turn shapes. In J. M. Atkinson \& J. Heritage (eds.), Structures of social action: Studies in conversation analysis (pp. 57-102). Cambridge: Cambridge University Press.

Pressing, J. (2002). Black atlantic rhythm: Its computational and transcultural foundations. Music Perception, 19(3), 285-310. doi:10.1525/mp.2002.19.3.285

Ravignani, A., Bowling, D. L., \& Fitch, W. T. (2014). Chorusing, synchrony, and the evolutionary functions of rhythm. Frontiers in Psychology, 5. doi:10.3389/fpsyg.2014.01118

Repp, B. H., \& Su, Y.-H. (2013). Sensorimotor synchronization: A review of recent research (2006-2012). Psychonomic Bulletin \& Review, 20(3), 403-452. doi:10.3758/s13423-012-0371-2

Sacks, H. (1974). An analysis of the course of a joke's telling in conversation. In R. Bauman \& J. Sherzer (eds.), Explorations in the ethnography of speaking (2nd ed., pp. 337-353). Cambridge: Cambridge University Press. doi:10.1017/CBO9780511611810.022

Sacks, H. (1986). Some considerations of a story told in ordinary conversations. Poetics, 15, 127-138.

Sacks, H. (1987). On the preferences for agreement and contiguity in sequences in conversation. In G. Button \& J. Lee (eds.), Talk and social organization (pp. 54-69). Clevedon: Multilingual Matters.

Sacks, H. (1995). Lectures on conversation. (G. Jefferson, ed.) (Vol. I,II). London: Wiley-Blackwell.

Schegloff, E. A. (1985). On some gestures' relation to talk. In J. M. Atkinson \& J. Heritage (eds.), Structures of social sction: Studies in conversation analysis (pp. 266-298). Cambridge: Cambridge University Press. doi:10.1017/CBO9780511665868.018

Schegloff, E. A. (1992). Repair after next turn: The last structurally provided defense of intersubjectivity in conversation. American Journal of Sociology, 97(5), 1295-1345.

Schegloff, E. A. (1996). Turn organization: One intersection of grammar and interaction. In E. Ochs, E. A. Schegloff, \& S. A. Thompson (eds.), Interaction and grammar (pp. 52-133). Cambridge University Press. doi:10.1017/СBO9780511620874.002

Schegloff, E. A., \& Sacks, H. (1973). Opening up closings. Semiotica, 8(4), 289-327. doi:10.1515/semi.1973.8.4.289 
Schegloff, E. A., Jefferson, G., \& Sacks, H. (1977). The preference for self-correction in the organization of repair in conversation. Language, 53(2), 361-382.

Schober, M. F., \& Spiro, N. (2014). Jazz improvisers' shared understanding: a case study. Frontiers in Psychology, 5(August), 1-21. doi:10.3389/fpsyg.2014.00808

Schütz, A. (1951). Making music together: A study in social relationship. Social Research, 18(1), 76-97.

Schütz, A. (1962). Phenomenology and the social sciences. In M. Natanson (ed.), Collected papers $i$ : The problem of social reality (pp. 118-139). Springer Netherlands. doi:10.1007/978-94-010-2851-6_5

Schütz, A. (1976). Tiresias, or our knowledge of future events. In A. Brodersen (ed.), Collected papers il (Vol. 15, pp. 277-293). Springer Netherlands. doi:10.1007/978-94-010-1340-6_13

Sheets-Johnstone, M. (1981). Thinking in movement. Journal of Aesthetics and Art Criticism, 39(4), 399407.

Stivers, T. (2008). Stance, alignment and affiliation during storytelling: when nodding is a token of affiliation. Research on Language and Social Interaction, 41(1), 31-57. doi:10.1080/08351810701691123

Suchman, L. A. (1987). Plans and situated actions: the problem of human-machine communication. Cambridge: Cambridge University Press.

Sudnow, D. (2001). Ways of the Hand: A Rewritten Account. Cambridge MA: MIT Press.

Tulbert, E., \& Goodwin, M. H. (2011). Choreographies of attention: Multimodality. In J. Streeck, C. Goodwin, \& C. LeBaron (eds.), Embodied interaction: Language and body in the material world (pp. 79-92). Cambridge: Cambridge University Press.

Wade, L. (2011). The emancipatory promise of the habitus: Lindy hop, the body, and social change. Ethnography, 12(2), 224-246. doi:10.1177/1466138111398231

Weeks, P. (1990). Musical time as a practical accomplishment: A change in tempo. Human Studies, 13(4), 323-359. doi:10.1007/BF00193569

Weeks, P. (2002). Performative error-correction in music: A problem for ethnomethodological description. Human Studies, 25(3), 359-385. doi:10.1023/A:1020182018989

Whalen, J., Whalen, M., \& Henderson, K. (2002). Improvisational choreography in teleservice work. The British Journal of Sociology, 53(2), 239-58. doi:10.1080/00071310220133322

Wooffitt, R., \& Holt, N. (2010). Silence and its organization in the pragmatics of introspection. Discourse Studies, 12(3), 379-406. doi:10.1177/1461445609358520 